\section{Predictors of Relapse in Patients with Opioid Addiction during Buprenorphine- Naloxone Maintenance Treatment}

\author{
Murat Kuloğlu ${ }^{1,2}$, Fatih Canan ${ }^{1,2 *}$, Ahmet Hakkı Aşık ${ }^{3}$, Hacer \\ Yalnız ${ }^{2}$, Nilüfer Yalınçetin ${ }^{2}$ and Ömer Geçici ${ }^{1,2}$ \\ ${ }^{1}$ Department of Psychiatry, Akdeniz University School of Medicine, Antalya, \\ Turkey \\ ${ }^{2}$ Alcohol and Substance Addiction Treatment and Research Center, \\ Akdeniz University, Antalya, Turkey \\ ${ }^{3}$ Psychiatry Clinic, Afyonkarahisar State Hospital, Afyonkarahisar, Turkey
}

\begin{abstract}
Background: Opioid abuse is an important public health issue. Buprenorphine-Naloxone Combination (BNC) is one of the most efficacious approaches for opioid withdrawal. Thus it is important to determine factors related with treatment outcomes in BNC maintenance treatment. Thus, we aimed to evaluate the predictors of three months compliance rate with BNC treatment among a sample of patients with opioid addiction.

Methods: In this retrospective study, we evaluated the records of patients who sought and had received any treatment with BNC for opioid addiction in an addiction treatment center during three months period. Relevant data such as socio-demographic variables, drug use history, and opioid use patterns were gathered from the records.

Results: At least three months after BNC maintenance treatment, relapse rate was $66.6 \%$. Patients who were not married and those with an education of less than 8 years were more likely to relapse to opioid use. We also found a relationship between average daily heroin doses and relapse as reflected by illicit opioid use during treatment.
\end{abstract}

Conclusions: Future research is needed to reveal whether determining these factors and establishing adequate interventions may lead to improved treatment outcomes.

Keywords: Buprenorphine-Naloxone; Maintenance treatment; Relapse

*Corresponding author: Fatih Canan, MD, Department of Psychiatry, Akdeniz University School of Medicine, 07059, Kampüs, Antalya, Turkey, Tel: +90242 2274400; Fax: +90 242 2275540; E-mail: fatihcanan@gmail.com

Citation: Kuloğlu M, Canan F, Aşık AH, Yalnız H, Yalınçetin N (2015) Predictors of Relapse in Patients with Opioid Addiction During Buprenorphine-Naloxone Maintenance Treatment. J Addict Addictv Disord 2: 005.

Received: December 15, 2014; Accepted: January 24, 2015; Published: February 06, 2015

Copyright: () 2015 Kuloğlu M, et al., This is an open-access article distributed under the terms of the Creative Commons Attribution License, which permits unrestricted use, distribution, and reproduction in any medium, provided the original author and source are credited.

\section{Introduction}

It is well-known that the use of opioids such as heroin is one of the most serious social and health problems in the world and $0.4 \%$ of the global population is estimated to abuse opioid drugs $[1,2]$. Opioid abuse is an important public health issue for Turkey as well [3]. The treatments of opioid dependence and withdrawal symptoms are of clinical importance. Currently, it has been accepted that buprenorphine, Buprenorphine-Naloxone Combination (BNC), and methadone are equally effective in maintenance therapy of opioiddependent patients and all of them have been shown to be more effective than placebo in relapse prevention [4-6]. In Turkey, however, only BNC is officially approved since April 2010 [7]. In addition, the prescription of BNC is limited by the Turkish Ministry of Health, allowing treatments only in specialized centers. Hence, the experience of maintenance treatment of opioid addiction is relatively low in Turkey. Up to now, no studies have examined factors associated with relapse and treatment retention in opioid dependent outpatients receiving BNC in Turkey.

The goal of this study was to evaluate the predictors of three months retention rate with buprenorphine-naloxone treatment among a sample of patients with opioid addiction.

\section{Materials and Methods}

A retrospective chart review of 60 patients with opioid addiction treated at the Akdeniz University, Alcohol and Substance Addiction Treatment and Research Center was conducted. Medical records of the patients were accessed via the center's database. We evaluated the records of all patients who sought and had received treatment with buprenorphine-naloxone for opioid addiction in the center from September 1, 2013 to November 31, 2013. Records were reviewed from the beginning of a patient's opioid treatment, through January 31,2014 , to ensure an opportunity for at least three months of data collection, even if the patient dropped out of treatment. Relevant data such as sociodemographic variables, drug use history, and opioid use patterns were gathered from the records.

Statistical analysis was done by SPSS statistical software (SPSS for windows 16.0, Inc., Chicago, IL, USA). The distribution of the data was tested using the Kolmogorov-Smirnov test. If distributed normally, data were shown as means and standard deviations and compared with Student's t-test. Non-normally distributed data were described as median ( $25^{\text {th }}$ percentile; $75^{\text {th }}$ percentile). The nonparametric Mann-Whitney $U$ test was used to detect differences in non-normally distributed continuous variables between patients who relapsed and those in retention. Age was the only normally distributed variable and all other continuous variables were found to be non-normally distributed. Categorical variables were compared using chi-square test.

\section{Results}

The mean ( \pm standard deviation) age of the study population was $25.7 \pm 6.7$ years. There were only four $(6.5 \%)$ females in the cohort. Most of the patients were single (78.3\%) and unemployed (65\%). At least three months after BNC maintenance treatment, relapse rate was 
Citation: Kuloğlu M, Canan F, Aşık AH, Yalnız H, Yalınçetin N (2015) Predictors of Relapse in Patients with Opioid Addiction During Buprenorphine-Naloxone Maintenance Treatment. J Addict Addictv Disord 2: 005.

$66.6 \%$. The comparison of patients who had relapsed and those who had not relapsed is presented in Table 1.

\begin{tabular}{|c|c|c|c|c|}
\hline & & $\begin{array}{l}\text { Relapse within } \\
3 \text { months } \\
(n=40)\end{array}$ & $\begin{array}{l}\text { Retention } \\
\text { within } 3 \\
\text { months } \\
(n=20)\end{array}$ & $P$ value \\
\hline $\mathrm{Age}^{*}$ & & $25.3(5.9)$ & $26.7(8.2)$ & 0.464 \\
\hline \multirow{2}{*}{ Gender** } & Female & $3(7.5)$ & $1(5)$ & \multirow{2}{*}{0.714} \\
\hline & Male & 37 (92.5) & $19(95)$ & \\
\hline \multirow{3}{*}{ Marital status ${ }^{* *}$} & Single & $35(87.5)$ & $12(60)$ & \multirow{3}{*}{0.020} \\
\hline & Married & $5(12.5)$ & $6(30)$ & \\
\hline & $\begin{array}{l}\text { Divorced/ } \\
\text { widowed }\end{array}$ & 0 & $2(10)$ & \\
\hline \multirow{4}{*}{ Education** } & 5 years & $8(20)$ & 0 & \multirow{4}{*}{0.017} \\
\hline & 8 years & $19(47.5)$ & $16(80)$ & \\
\hline & 11 years & $12(30)$ & $2(10)$ & \\
\hline & $>11$ years & $1(2.5)$ & $2(10)$ & \\
\hline \multirow{2}{*}{ Employment status ${ }^{* *}$} & Employed & $14(35)$ & $7(35)$ & \multirow{2}{*}{0.616} \\
\hline & Unemployed & $26(65)$ & $13(65)$ & \\
\hline \multirow{4}{*}{$\begin{array}{l}\text { Duration of opioid } \\
\text { use prior to } \\
\text { treatment* }\end{array}$} & $<1$ year & $3(7.5)$ & $5(25)$ & \multirow{4}{*}{0.173} \\
\hline & $1-3$ years & $7(17.5)$ & $4(20)$ & \\
\hline & $4-5$ years & $14(35)$ & $3(15)$ & \\
\hline & $>5$ years & $16(40)$ & $8(40)$ & \\
\hline \multirow{2}{*}{$\begin{array}{l}\text { Comorbid cannabis } \\
\text { use }\end{array}$} & Yes & $7(17.5)$ & $5(25)$ & \multirow{2}{*}{0.494} \\
\hline & No & $33(82.5)$ & $15(75)$ & \\
\hline \multirow{2}{*}{$\begin{array}{l}\text { History of suicide } \\
\text { attempt }\end{array}$} & Yes & $10(25)$ & $2(10)$ & \multirow{2}{*}{0.171} \\
\hline & No & $30(75)$ & $18(90)$ & \\
\hline $\begin{array}{l}\text { Age of first heroin } \\
\text { use }{ }^{\star \star *}\end{array}$ & & $21(16 ; 23)$ & $\begin{array}{c}21.5 \\
(16.5 ; 24.8)\end{array}$ & 0.349 \\
\hline $\begin{array}{l}\text { Average daily heroin } \\
\text { dose prior to } \\
\text { treatment (g/day) }\end{array}$ & & $0.9(0.4 ; 1)$ & $1(0.8 ; 3)$ & 0.029 \\
\hline
\end{tabular}

Table 1: Comparison of patients with relapse and retention.

*Mean (standard deviation), Student's t-test; ${ }^{* *}$ Number (percentile), chi-square test ${ }^{* * *}$ Median (25th percentile; 75 th percentile), Mann-Whitney U test.

\section{Discussion}

This study investigated the predictors of retention to BNC treatment in patients with opioid dependence. We found that marital and education statuses were predictors of relapse. Moreover, higher average daily heroin dose prior to maintenance treatment was associated with patient relapse.

Relapse rates during $\mathrm{BNC}$ treatment have been reported to vary significantly ranging from $13 \%$ to $40.8 \%$ in 3 months [8-10]; $39.6 \%$ to $51.6 \%$ in 6 months [11-14]; and $21.7 \%$ to $25 \%$ in 12 months period $[15,16]$. When compared with previous findings, we observed a relatively high relapse rate within 3 months in our study. This finding may be interpreted by the relatively short time of experience with BNC treatment in Turkey. High relapse rates in BNC treatment warrants further evaluation of predicting factors associated with relapse.

Only a few studies have investigated the factors predicting relapse in BNC maintenance treatment. Tkacz et al., [9] have found that none of the socio-demographic features noted at baseline were predictive of relapse in 3 months follow up in BNC treatment. Ferri et al., [12], evaluating the chart review of 62 patients with opioid addiction, have shown that patients with comorbid anxiety disorders, active benzodiazepine use, or active alcohol abuse, were significantly more likely to relapse. In another study [10], however, higher rate of baseline depression was found to be associated with treatment compliance. Buprenorphine has been shown to be effective in treatment-resistant depression $[17,18]$. Thus, patients with depressive symptoms may benefit from BNC treatment and this may enhance treatment motivation. Moreover, the records of 69 US veterans who were receiving BNC treatment for opioid use disorder were evaluated and patients with a comorbid psychiatric disorder were found more frequently to be noncompliant to treatment [16]. Additional factors predicting relapse were comorbid benzodiazepine or cannabis use [19]. In our study, however, comorbid cannabis use was not associated with relapse.

Several limitations have to be considered when interpreting the findings of the present study. First, the retrospective design of the study may hinder establishing causality. Second, the study sample was relatively small to draw definite conclusions. Third, the follow up period was relatively short ( 3 months) and our findings do not shed light on long term results. Also, we did not conduct power analyses to calculate sample size.

Our results suggest that patients who were not married and those with an education of less than 8 years were more likely to relapse to opioid use. We also found a relationship between average daily heroin dose and relapse during treatment. The reason for this finding may indicate inadequate $\mathrm{BNC}$ dose among heroin dependent patients who use higher doses. Future research is needed to reveal whether determining these factors and establishing adequate interventions may lead to improved treatment outcomes.

\section{References}

1. Nurco DN, Ball JC, Shaffer JW, Hanlon TE (1985) The criminality of narcotic addicts. J Nerv Ment Dis 173: 94-102.

2. Compton WM, Volkow ND (2006) Major increases in opioid analgesic abuse in the United States: concerns and strategies. Drug Alcohol Depend 81: 103107.

3. Toprak S, Cetin I (2009) Heroin overdose deaths and heroin purity between 1990 and 2000 in Istanbul, Turkey*. J Forensic Sci 54: 1185-1188.

4. Mattick RP, Ali R, White JM, O'Brien S, Wolk S, et al. (2003) Buprenorphine versus methadone maintenance therapy: a randomized double-blind trial with 405 opioid-dependent patients. Addiction 98: 441-452.

5. Boothby LA, Doering PL (2007) Buprenorphine for the treatment of opioid dependence. Am J Health Syst Pharm 64: 266-272.

6. Dennis BB, Naji L, Bawor M, Bonner A, Varenbut M, et al. (2014) The effectiveness of opioid substitution treatments for patients with opioid dependence: a systematic review and multiple treatment comparison protocol. Syst Rev 3: 105.

7. TC Ministry of Health General Directorate of Pharmaceuticals and Pharmacy (2010): November 23, 2009 Circular No. 079,661(2009/74) and October 14, 2010 Circular No. 070,068 (2010/72).

8. Tkacz J, Severt J, Cacciola J, Ruetsch C (2012) Compliance with buprenorphine medication-assisted treatment and relapse to opioid use. Am J Addict 21: $55-62$.

9. Dean AJ, Bell J, Christie MJ, Mattick RP (2004) Depressive symptoms during buprenorphine vs. methadone maintenance: findings from a randomised, controlled trial in opioid dependence. Eur Psychiatry 19: 510-513. 
Citation: Kuloğlu M, Canan F, Aşı AH, Yalnız H, Yalınçetin N (2015) Predictors of Relapse in Patients with Opioid Addiction During Buprenorphine-Naloxone Maintenance Treatment. J Addict Addictv Disord 2: 005.

- Page 3 of 3 •

10. Gerra G, Borella F, Zaimovic A, Moi G, Bussandri M, et al. (2004) Buprenorphine versus methadone for opioid dependence: predictor variables for treatment outcome. Drug Alcohol Depend 75: 37-45.

11. Pani PP, Maremmani I, Pirastu R, Tagliamonte A, Gessa GL (2000) Buprenorphine: a controlled clinical trial in the treatment of opioid dependence. Drug Alcohol Depend 60: 39-50.

12. Ferri M, Finlayson AJ, Wang L, Martin PR (2014) Predictive factors for relapse in patients on buprenorphine maintenance. Am J Addict 23: 62-67.

13. Stein MD, Cioe P, Friedmann PD (2005) Buprenorphine retention in primary care. J Gen Intern Med 20: 1038-1041.

14. Soyka M, Zingg C, Koller G, Kuefner H (2008) Retention rate and substance use in methadone and buprenorphine maintenance therapy and predictors of outcome: results from a randomized study. Int J Neuropsychopharmacol 11: $641-653$

15. Maremmani I, Pani PP, Pacini M, Perugi G (2007) Substance use and quality of life over 12 months among buprenorphine maintenance-treated and methadone maintenance-treated heroin-addicted patients. J Subst Abuse Treat 33: 91-98.
16. Kakko J, Svanborg KD, Kreek MJ, Heilig M (2003) 1-year retention and social function after buprenorphine-assisted relapse prevention treatment for heroin dependence in Sweden: a randomised, placebo-controlled trial. Lancet 361: 662-668.

17. Bodkin JA, Zornberg GL, Lukas SE, Cole JO (1995) Buprenorphine treatment of refractory depression. J Clin Psychopharmacol 15: 49-57.

18. Karp JF, Butters MA, Begley AE, Miller MD, Lenze EJ, et al. (2014) Safety, tolerability, and clinical effect of low-dose buprenorphine for treatment-resistant depression in midlife and older adults. J Clin Psychiatry 75: 785-793.

19. Fareed A, Eilender P, Ketchen B, Buchanan-Cummings AM, Scheinberg K, et al. (2014) Factors affecting noncompliance with buprenorphine maintenance treatment. J Addict Med 8: 345-350. 